\title{
Dynamic vehicle routing in road evacuation: a model for route design
}

\author{
A. Polimeni \& A. Vitetta \\ Università degli Studi Mediterranea di Reggio Calabria, \\ DIMET - Dipartimento di Informatica, Matematica, Elettronica \\ e Trasporti, Italy
}

\begin{abstract}
In this paper the shortest path and route problem in time-dependent networks are treated. The system can be in ordinary or emergency conditions. Path design formulation is based on dynamic programming and its solution is found through a modification of Dijkstra's algorithm. Route design, starting from the designed paths, is formulated as an optimum problem. In emergency conditions the main objective is to optimize emergency vehicle tour to reduce the intervention time or maximize the number of people rescued in a fixed time.
\end{abstract}

Keywords: time-dependent networks, path design, emergency conditions.

\section{Introduction}

Models and procedures to find shortest paths in a road network in real time are essential to provide information to system users. In this paper we propose models and procedures for path design, and accordingly for vehicle route design, for a fleet of emergency vehicles that operate to support the population involved in a disaster. When a disaster occurs, the road network changes from ordinary conditions to emergency conditions (i.e. due to the closure of some links, to the change in link costs, and so on). For a road network under emergency conditions, models and procedures used for networks under ordinary conditions cannot be directly applied [1]. In emergency conditions many of the models and procedures used in ordinary conditions need to be redefined. The modifications to be considered concern demand [2-6], supply and demand-supply interaction [7, 8], path design for emergency vehicles $[9,10]$ and the general guidelines for planning [11-15]. 
A path is a link sequence, without loops, that connects an initial node (origin) to a final node (destination). A vehicle route is a path sequence which a vehicle uses to reach some points (nodes) in a road network. Hence path design consists in optimizing the link sequence; the route design consists in optimizing the path sequence in a route, termed path succession.

Path design [9] consists in the solution of a One-to-One Problem (OOP), and route design in solving a Many-to-One Problem (MOP) (known as Vehicle Routing Problem, VRP).

The models and methods found in the literature appear unable to tackle the OOP and the VRP in emergency conditions, due to the major changes arising in supply and demand when an emergency occurs. Such changes affect the path choice dimension, hence that of vehicle routing, since a vehicle route is the result of a combination of different paths in which travel time rapidly changes.

From the above considerations there emerged the need to integrate the design models in the literature with considerations made for a network in emergency conditions, in order to allow for the effects of variation in supply and demand in path and vehicle routing definitions. Moreover, the evolution of network costs also needs to be taken into account so as to be able to update path topology and routes in time. In a time-dependent network, a path is termed time-dependent when at least one link has a cost function dependent on time. Similarly, a timedependent route is a route in which at least one path is time-dependent.

The main research advances presented in this paper concern the design models, which are able to optimize paths and routes for emergency vehicles, taking into account time-dependence and optimizing the wait times at the nodes.

The paper is structured as follows. In section 2 a literature review concerning the shortest paths search in time-dependent networks is presented. Section 3 reports the approach to find the best paths and routes. Finally, in section 4, are the conclusions and possible future developments.

\section{Literature review}

In this section, the literature related to the OOP and VRP is examined. Previous emphasis has been on path and route design for networks in ordinary conditions, and path search is based on Bellman's optimality condition [16]. The shortest path problem can be solved using a dynamic programming approach $[16,17]$.

Static networks (that is when the link cost is invariable in time) have been widely covered literature; for an extensive literature review, see [9, 18]. For time-dependent networks, one of the first path search studies was made by Cooke and Halsey [19], in which the travel time between two nodes depends on departure time from the first node. Next, Dreyfus [20] evaluated some algorithms for the shortest path search, especially the case in which the link costs (link lengths) are time-dependent. In the literature, the problem is generally defined as being how to find the paths from one node to all the others or vice versa. Under certain assumptions [21], the two problems are symmetric and can be solved in an equivalent manner. Another consideration may be made on the type of approach, deterministic ([22-24] to name a few) or stochastic (for example [25- 
28]). In the former, the costs are variable in time and for each time value we have a single cost value; in the latter the costs are random variables with a probability distribution function and for each time value may have some cost value with a certain probability. In some papers [29, 30], path search is analysed with the possibility of waiting at intermediate nodes.

There are also other cases [31] in which the waiting time at intermediate nodes to reduce the cost of the path is added. In this case the link cost functions are continuous and the proposed algorithm is a modification of Dijkstra's algorithm. Note that the path topology is fixed and cannot be changed by inserting the waiting time at the nodes.

Much has been written about the VRP with static costs in ordinary conditions. For an extensive literature review related to VRP see [32]. The VRP in emergency conditions is discussed in [9, 33]. Some papers discuss the case of vehicle routing with time-dependent costs in a network in ordinary conditions $[34,35]$.

\section{Proposed approach}

\subsection{Notation}

Let:

$i, j$ be the initial and final node of the link (i,j);

$\mathrm{v}$, a vehicle;

$\mathrm{A}_{\mathrm{i}, \mathrm{v}}$, the instant of arrival at node $\mathrm{i}$ by vehicle $\mathrm{v}$;

$\chi_{\mathrm{ij}}(\mathrm{t})$, the cost function for the link $(\mathrm{i}, \mathrm{j})$ (the function defines the ij travel link cost for vehicle $\mathrm{v}$ which arrives at node $\mathrm{i}$ in instant $\mathrm{t}$ );

$\omega_{\mathrm{i}}(\mathrm{t})$, the waiting function at node $\mathrm{i}$;

$\lambda_{\mathrm{ij}}(\mathrm{t})=\chi_{\mathrm{ij}}(\mathrm{t})+\omega_{\mathrm{i}}(\mathrm{t})$;

$\mathrm{A}^{*}{ }_{\mathrm{i}, \mathrm{v}}$, the instant when $\lambda_{\mathrm{ij}}(\mathrm{t})$ is minimum with $\mathrm{t} \geq \mathrm{A}_{\mathrm{i}, \mathrm{v}}$;

$\mathrm{w}_{\mathrm{i}, \mathrm{j}, \mathrm{v}}^{*}=\mathrm{A}_{* \mathrm{i}, \mathrm{v}}^{*}-\mathrm{A}_{\mathrm{i}, \mathrm{v}}$

Below, $w^{*}{ }_{i, j, v}$ stands for optimum Waiting time at node $\mathrm{i}$ to reach $\mathrm{j}$.

\subsection{Cost functions analysis}

In a network under emergency conditions two vehicle classes can be distinguished: private user vehicles and emergency vehicles. When a vehicle moves on the network it incurs a cost which depends on time according to some functions. Generally, emergency vehicles have priority but, if the vehicles are moving in a mixed lane, they may be constrained by the time of private user vehicles. In such conditions, it can be assumed that the time-dependent cost functions for emergency vehicles are the same as those considered for private vehicles. Hence, function $\chi_{\mathrm{ij}}(\mathrm{t})$ is defined by the travel time of private vehicles; the emergency vehicles do not modify this travel time because they are far fewer in number than private vehicles. This assumption allows us to guide emergency vehicles along a best path. 
The path cost is the sum of the link cost, for the link belonging to the path, and node wait, when waiting is allowed. The following analysis reported in this section is made by setting the instant of arrival at node $i$ by vehicle $v\left(\mathrm{~A}_{\mathrm{i}, \mathrm{v}}\right.$ is fixed) and analysing the system at time $t \geq A_{i, v}$. This analysis is general because on changing time or node the problem is recursive.

To simplify the notation, this section will not consider the subscripts of the variables related to the nodes and vehicles, and the following notation is used:

A, the instant of arrival at node $\mathrm{i}$ by vehicle $\mathrm{v}$;

$\mathrm{A}^{*}$, the instant when $\lambda(\mathrm{t})$ is minimum;

$\mathrm{w}^{*}$, the optimum waiting time;

$\chi(\mathrm{t})$, the cost function for the link;

$\omega(\mathrm{t})$, waiting function at the node;

$$
\lambda(\mathrm{t})=\chi(\mathrm{t})+\omega(\mathrm{t})
$$

For the link cost some types of continuous cost function $\chi(\mathrm{t})$ are utilized. For the waiting time function a linear function is assumed with unitary slope (other functions could be used):

$$
\omega(\mathrm{t})=\mathrm{t}-\mathrm{A} \quad \text { with } \mathrm{t} \geq \mathrm{A} .
$$

In the cases where the link cost function is decreasing, waiting at the node could allow a cost reduction. Conversely, an increasing function may not lead to a cost reduction if it optimizes the wait at the initial node. To optimize the cost $\lambda(t)$ it is necessary to optimize the waiting time $w^{*}$ at the nodes.

Simple geometrical considerations allow us to identify the range where $\mathrm{w}^{*}$ could fall. In figure 1 the case of a general link cost function is examined. In figure 1 the cost function $\chi(\mathrm{t})$ is indicated by a broken line, the auxiliary function $\lambda(\mathrm{t})$ by a solid line. A dotted line is used for the waiting function $\omega(\mathrm{t})$, starting from the arrival time A.

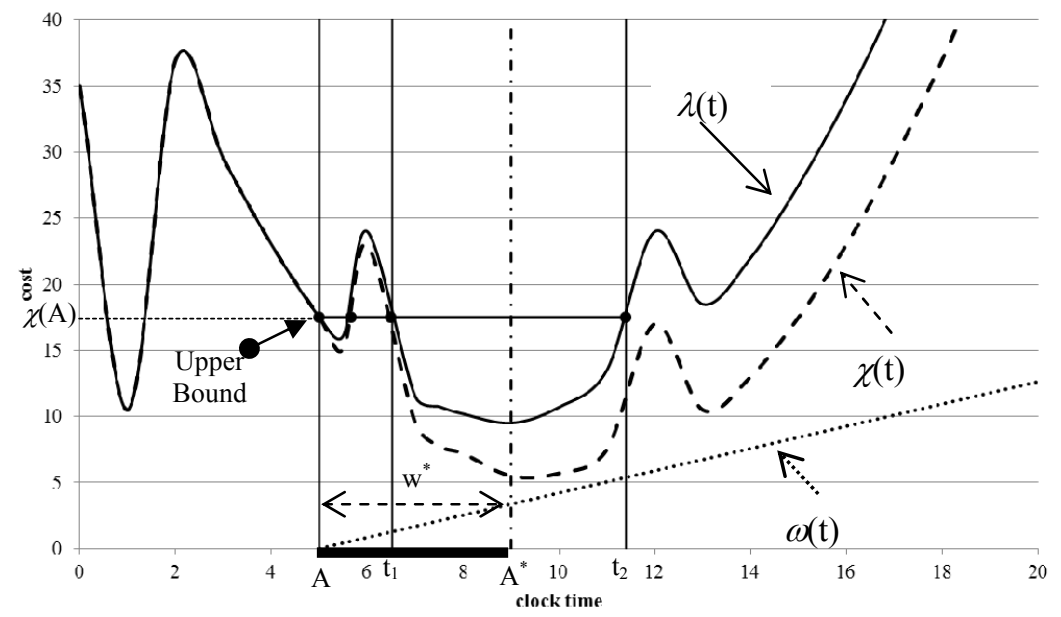

Figure 1: $\quad$ Arrival time and optimum waiting time in a general case. 
Given an arrival time $\mathrm{A}$, the cost is $\chi(\mathrm{A})$ (that is equal to $\lambda(\mathrm{A})$ ). It represents an upper bound for the link cost (the link cost will be less than or equal to the upper bound value). This value may not be unique: on drawing a horizontal line from point $(\mathrm{A}, \chi(\mathrm{A}))$ it is possible to identify some other points $\left(\mathrm{t}_{\mathrm{x}}, \chi(\mathrm{A})\right)$ where the cost is the same. Figure 1 shows points $t_{1}$ and $t_{2}$ which have the discussed property. If the function admits values below the upper bound, this means that the wait at the starting node could reduce the link cost. It may then be stated that there could be an optimum departure instant $\mathrm{A}^{*}\left(\mathrm{~A}^{*} \geq \mathrm{A}\right)$, and an optimum waiting time $\mathrm{w}^{*}=\mathrm{A}^{*}-\mathrm{A}$. It may be seen that $\mathrm{A}^{*}$ exists and at the limit $\mathrm{A}^{*}$ is equal to $\mathrm{A}$.

An alternative method to locate $A^{*}$ is to draw a half-line with slope $\pi / 4$ starting from the arrival point (A, $\chi(\mathrm{A}))$. Point $\mathrm{t}^{*}$ is to be found in the half space where $\chi(\mathrm{t})$ is below the half-line.

The function $\chi(\mathrm{A})$ is obtained from forecast data [36, 37], and several specifications can be adopted. In the following, some particular cost functions are analysed.

\subsubsection{Linear functions}

In the linear case (figure 2), we assume that the cost function for each link is:

$$
c=\chi(\mathrm{t})=\mid \begin{array}{ll}
\mathrm{a}+\mathrm{b} \cdot \mathrm{t} & \text { if } \mathrm{c} \geq \mathrm{c}_{0} \\
\mathrm{c}_{0} & \text { if } \mathrm{c}<\mathrm{c}_{0}
\end{array}
$$

subject to:

$$
\begin{aligned}
& \mathrm{t} \geq 0 \\
& \mathrm{a} \geq 0 \\
& \mathrm{c}_{0} \geq 0
\end{aligned}
$$

Parameter $a$ is the link cost at instant $\mathrm{t}=0$, constraint (2) ensures time positivity, and constraint (3) ensures that the link cost is non-negative. Let:

$$
\mathrm{A}^{*}=\left(\mathrm{c}_{0}-\mathrm{a}\right) / \mathrm{b}
$$

be the point of discontinuity of the function, that in this case is also the minimum point.

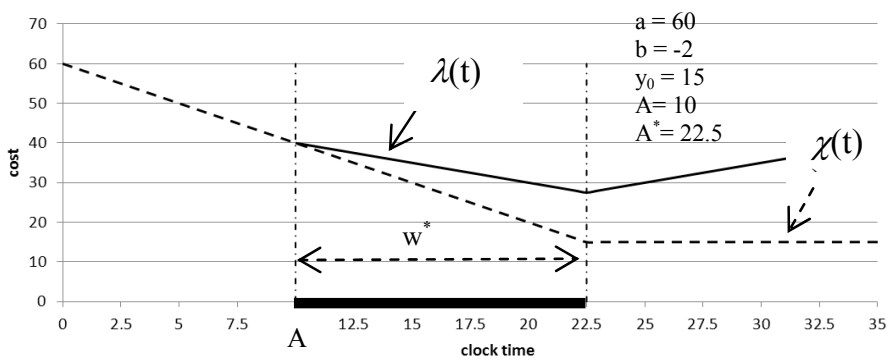

Figure 2: Waiting time for linear functions. 


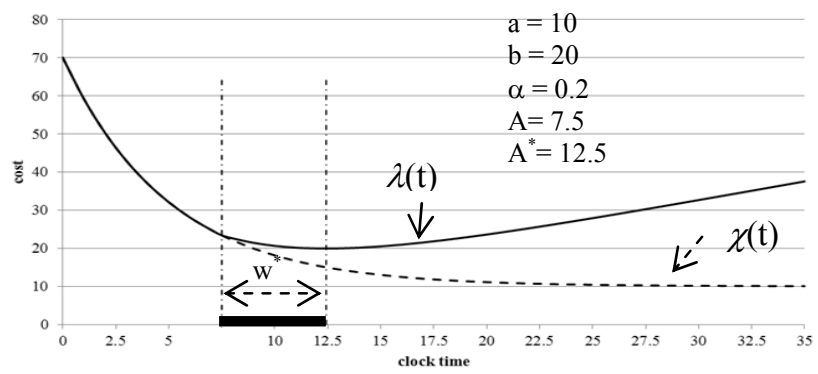

Figure 3: Waiting time for exponential functions.

In this case, the auxiliary function $\lambda(\mathrm{t})$ is:

$$
\mathrm{I}=\lambda(\mathrm{t})=\mathrm{d} \cdot \mathrm{t}+\mathrm{e} \quad \text { if } \mathrm{A} \leq \mathrm{t}
$$

with $d=b+1$ and $e=b-A$.

The waiting time greater than zero, in this particular case, is allowed when $\lambda(\mathrm{t})$ is decreasing, hence when $\mathrm{d}<0$ :

$$
\mathrm{d}=(\mathrm{b}+1)<0 \rightarrow \mathrm{b}<-1
$$

The previous condition implies that a cost function with $b<-1$ allows the waiting time at the node.

\subsubsection{Exponential functions}

In the exponential case (figure 3), we assume the cost function for each link as:

subject to (2), (3), (4).

$$
\mathrm{c}=\chi(\mathrm{t})=\mathrm{a}+\mathrm{b} \cdot \exp (-\alpha \cdot \mathrm{t})
$$

The sum of the parameters $a$ and $b$ is the link cost in the instant $\mathrm{t}=0$, the constraints ensure time and cost congruence.

In this case, the auxiliary function $\lambda(\mathrm{t})$ is:

$$
1=\lambda(\mathrm{t})=\mathrm{a}+\mathrm{b} \cdot \exp (-\alpha \cdot \mathrm{t})+(\mathrm{t}-\mathrm{A}) \quad \text { if } \mathrm{A} \leq \mathrm{t}
$$

The function $\lambda(\mathrm{t})$ admits a minimum at the point:

$$
\mathrm{A}^{*}=\ln (\alpha \cdot \mathrm{b}) / \alpha
$$

and the optimum waiting time is: $\mathrm{w}^{*}=\ln (\alpha \cdot \mathrm{b}) / \alpha-\mathrm{A}$

\subsubsection{Periodic functions}

In the periodic case (figure 4), we assume that the cost function for each link is:

$$
\mathrm{c}=\chi(\mathrm{t})=\mathrm{a}+\mathrm{b} \cdot \sin (2 \pi \cdot \mathrm{t} / \mathrm{T}+\phi)
$$

subject to (2), (3). Here $b \leq a$ (to ensure that the cost is a positive value) where: $\mathrm{T}$ is the period;

$\phi$ is the phase difference.

In this case, the auxiliary function $\lambda(\mathrm{t})$ is:

$$
1=\lambda(\mathrm{t})=\mathrm{a}+\mathrm{b} \cdot \sin (2 \pi \cdot \mathrm{t} / \mathrm{T}+\phi)+(\mathrm{t}-\mathrm{A}) \quad \text { if } \mathrm{A} \leq \mathrm{t}
$$


The function $\lambda(\mathrm{t})$ admits a minimum at the point (to recall that the minimum is repeated at regular intervals):

and the optimum waiting time is:

$$
\mathrm{A}^{*}=(\mathrm{T} / 2 \pi) \cdot(-\operatorname{arcos}(-\mathrm{T} / 2 \pi \cdot \mathrm{b})+(2 \pi-\phi))
$$

$$
\mathrm{w}^{*}=(\mathrm{T} / 2 \pi) \cdot(-\operatorname{arcos}(-\mathrm{T} / 2 \pi \cdot \mathrm{b})+(2 \pi-\phi))-\mathrm{A}
$$

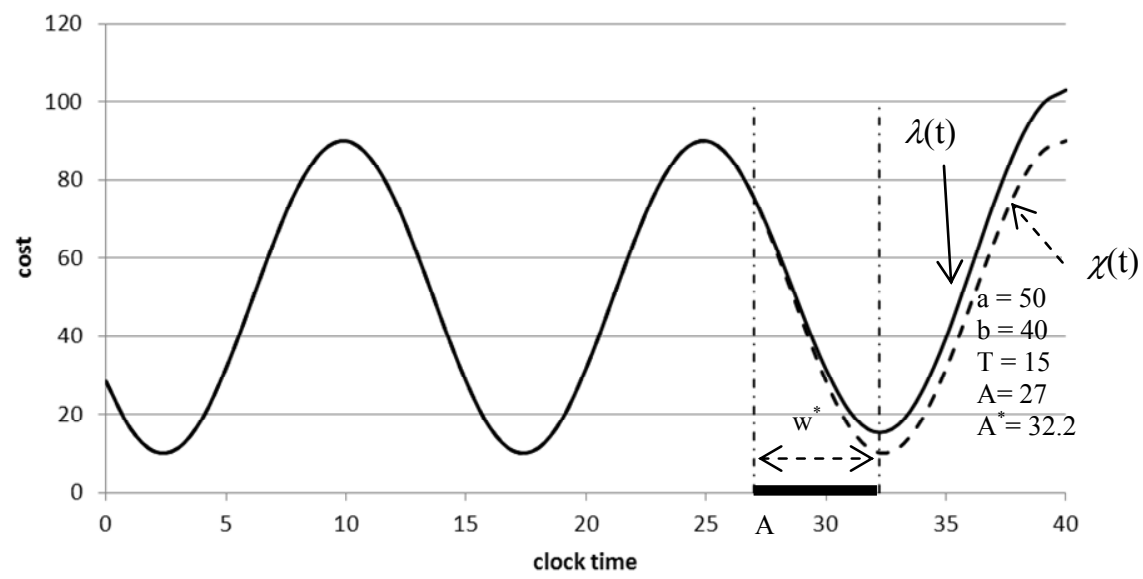

Figure 4: Waiting time for periodic functions.

In table 1 the discussed functions are reported, with some considerations on the parameters.

\begin{tabular}{|c|c|c|c|c|}
\hline Cost function & Graphic $^{*}$ & & meters & $\mathrm{w}^{*}$ \\
\hline \multirow{2}{*}{$\chi(\mathrm{t})=\mathrm{a}+\mathrm{b} \cdot \mathrm{t}$} & & \multirow{2}{*}{$a>0$} & $b>0$ & $=0$ \\
\hline & 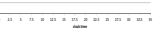 & & $\mathrm{b}<0$ & $=\left(c_{0}-a\right) / b-A$ \\
\hline \multirow{2}{*}{$\chi(\mathrm{t})=\mathrm{a}+\mathrm{b} \cdot \exp (\alpha \cdot \mathrm{t})$} & & \multirow{2}{*}{$a>0, \alpha>0$} & $\alpha b \leq 0$ & $=0$ \\
\hline & 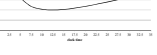 & & $\alpha b>0$ & $=(1 / \alpha) \cdot \ln (\alpha b)-A$ \\
\hline \multirow{2}{*}{$\chi(\mathrm{t})=\mathrm{a}+\mathrm{b} \cdot \sin (2 \pi \cdot \mathrm{t} / \mathrm{T}+\phi)$} & $\sqrt{\sim}$ & \multirow{2}{*}{$\begin{array}{l}a>0, b>0 \\
b \leq a, T>0\end{array}$} & $\begin{array}{l}\mathrm{T} / 2 \pi \cdot \mathrm{b}>1 \\
\mathrm{~T} / 2 \pi \cdot \mathrm{b}<-1\end{array}$ & $=0$ \\
\hline & 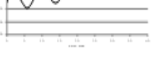 & & $-1 \leq(\mathrm{T} / 2 \pi \cdot \mathrm{b}) \leq 1$ & $\begin{array}{l}=(\mathrm{T} / 2 \pi) \cdot(-\operatorname{arcos}(\mathrm{T} / 2 \pi \cdot \mathrm{b})+ \\
+(2 \pi-\phi))-\mathrm{A}\end{array}$ \\
\hline
\end{tabular}

Table 1: $\quad$ Cost function characteristics.

* cost function + waiting function 
Let $\mathrm{C} \subseteq \mathrm{N}$ be the set of centroid nodes, each centroid corresponding to the beginning and end of a path.

Let $c_{\mathrm{jj}}$ be the cost of link $(\mathrm{i}, \mathrm{j})$ :

$\mathrm{c}_{\mathrm{ij}}=\mid \begin{array}{ll}\text { a time-dependent finite and positive value } & \begin{array}{l}\text { if the link exists } \\ +\infty\end{array} \\ \text { otherwise }\end{array}$

A path $k$ is a sequence of consecutive links (without loops) connecting an initial node $o(\mathrm{o} \in \mathrm{C})$ to a final node $d(\mathrm{~d} \in \mathrm{C})$. If we associate the graph with the cost functions $\lambda(\mathrm{t})$, it is termed a network $\mathrm{R}(\mathrm{G}, \lambda(\mathrm{t}))$.

The shortest paths in a network are characterized by the topology (ordered sequence of nodes belonging to the path) and by the cost (sum of the costs of the links belonging to the path and any other costs). Let $\mathrm{z}_{\mathrm{j}}$ be the shortest path cost from origin $o$ to node $j$ (using this definition, $\mathrm{z}_{\mathrm{o}}=0$ for each origin).

In a time-dependent network to build the shortest paths tree, a departure time $\mathrm{t}_{0}$ is set from origin $o$. All the other time values $\mathrm{z}_{\mathrm{j}}(11)$ refer to $\mathrm{t}_{0}$ (that can be set $\mathrm{t}_{0}=0$ without losing generality):

$$
\mathrm{z}_{\mathrm{i}}=\mathrm{z}_{\mathrm{i}}\left(\mathrm{t}_{0}\right)
$$

The shortest path search is based on a time-generalized Bellman optimality condition:

$$
\mathrm{z}_{\mathrm{j}}=\operatorname{argMin}_{\mathrm{t}, \mathrm{t} \geq \mathrm{Ai}, \mathrm{v}, \mathrm{i} \neq \mathrm{j}}\left(\mathrm{A}_{\mathrm{i}, \mathrm{v}}+\lambda_{\mathrm{ij}}(\mathrm{t})\right)
$$

where the problem variables are time-dependent.

To solve the OOP, a Dijkstra modified algorithm is used.

\subsubsection{Existence}

\section{Theorem 1}

At the beginning of this section a network was defined as a graph that has some cost associated functions. A connected network is a network where there is always at least one path between each origin/destination pair. In a connected transport network, for each origin, the shortest path tree with roots in the origin node can always be built.

\subsubsection{Uniqueness}

Theorem 2 In a connected network, with non-negative link costs, there is a unique solution to equation (13). Note that this theorem does not imply the uniqueness of the shortest path tree: there may be more than one shortest path tree but the cost vector $\mathbf{z}$ (with component $\mathrm{z}_{\mathrm{j}}$ the shortest path cost from origin $o$ to node $j$ ) is always the same.

\section{Let}

$\mathrm{t}_{0}$ be the departure instant from the origin;

$\mathbf{z}={ }^{\mathrm{T}}\left[\mathrm{z}_{1}, \mathrm{z}_{2}, \ldots, \mathrm{z}_{\mathrm{n}}\right]$ be the cost vector considering a short path tree;

$\mathbf{u}={ }^{\mathrm{T}}\left[\mathrm{u}_{1}, \mathrm{u}_{2}, \ldots, \mathrm{u}_{\mathrm{n}}\right]$ be another possible solution to equation (13) such that $\mathrm{u}_{\mathrm{j}} \neq \mathrm{z}_{\mathrm{j}}$ for some nodes $j$. 
Without losing generality we can assume that for all nodes except one, the costs are equal:
$\mathrm{u}_{\mathrm{i}}=\mathrm{z}_{\mathrm{i}}$
$\forall \mathrm{i} \neq \mathrm{i}$
$\mathrm{u}_{\mathrm{i}} \neq \mathrm{z}_{\mathrm{i}}$

As the cost $z_{j}$ is a shortest path cost, then $u_{j}>z_{j}$.

Since $\mathbf{z}$ and $\mathbf{u}$ are solutions of (13):

$$
\begin{aligned}
& z_{j}=z_{i}+\lambda_{i j}\left(A_{i, v}\right) \\
& u_{j}=u_{i}+\lambda_{i j}\left(A_{i, v}\right)
\end{aligned}
$$

$z_{i}$ being equal to $u_{i}$, we have the same cost $\lambda_{i j}(t)$ in both cases (since the cost depends on the arrival time at the first node of the link). But, $u_{j}$ being greater than $z_{j}$, then $u_{j}>z_{i}+\lambda_{i j}\left(A_{i, v}\right)$ and hence we should have $u_{j}>u_{i}+\lambda_{i j}\left(A_{i, v}\right)$ against the time-generalized Bellman optimality condition. Thus vector $\mathbf{z}$ is unique. The demonstration can be extended to the case where condition (13) has occurred on more than one node.

\subsection{VRP model}

The VRP can be formulated as an optimum problem; the output is a node client sequence for each vehicle.

Let:

$\mathrm{z}_{\mathrm{i}}\left(\mathrm{t}_{0}\right)$, the shortest path cost from the origin to node $i$, starting from the origin at $\mathrm{t}_{0}$ $(i \in C)$;

$\mathrm{Z}_{\mathrm{i}, \mathrm{j}}\left(\mathrm{t}_{0}\right)$, the shortest path cost from node $j$ to node $i$, starting from node $j$ at $\mathrm{t}_{0}(\mathrm{i}, \mathrm{j}$ $\in \mathrm{C})$;

$\mathrm{Z}_{\mathrm{i}, \mathrm{j}}(\mathrm{t})$, the shortest path cost from node $j$ to node $i$, starting from node $j$ at $\mathrm{t}(\mathrm{i}, \mathrm{j} \in$ C).

The problem can be formulated as:

$$
\zeta=\operatorname{argMin}_{\xi} \sum_{\mathrm{i}} \sum_{\mathrm{j}} \sum_{\mathrm{\kappa}} \mathrm{z}_{\mathrm{i}, \mathrm{j}}(\mathrm{t}) \bullet \xi_{\mathrm{i}, \mathrm{j}, \mathrm{\kappa}}
$$

subject to:

capacity constraints (for each vehicle the capacity cannot be violated); congruence constraints (a user cannot be reached more than once, all vehicles return to the starting point);

where: time-dependent constraints.

$\zeta$ is the solution cost;

$\xi_{i, j, \kappa}$ is a binary variable equal to 1 if the path between $i$ and $j(i, j \in C)$ belong to route $\kappa$, zero otherwise;

Route design is made considering the time-dependent paths. This assumption implies that the routes are also time-dependent. Note that in a route consisting of $\mathrm{n}$ nodes the cost of the path linking node $\mathrm{j}-1$ with node $\mathrm{j}$ depends on departure time (arrival time + waiting) at node $\mathrm{j}-1$.

To solve the VRP, a genetic algorithm could be used, which allows a solution to be found close to the optimal but with smaller computation times than an exact algorithm. 


\section{Conclusions}

This paper tackled the path and route design problem in a time-dependent network. After an overview of the models and procedures found in the literature, for path design we proposed a one-to-one problem in time-dependent networks. Its formulation was based on dynamic programming, considering the timegeneralized Bellman optimality condition. The solution procedure was based on Dijkstra's algorithm. The route design proposed is a vehicle routing problem integrated with the above path design, whose formulation is an optimum problem with the aim of route cost minimization.

The main contribution of the paper concerns the design models, applied to optimize paths and routes for emergency vehicles in an evacuation scenario. The paths and routes are designed by taking into account the properties of a timedependent network. In the application on a real network, the data (obtained with real time observations) are integrated with forecast data (to define the costs on non-observed network elements). In the future, the shortest paths algorithm will be implemented both on test and real networks.

\section{References}

[1] Russo F. \& Vitetta A., Risk evaluation in a transportation system. International Journal of Sustainable Development and Planning, 1 (2), pp. 170-191, 2006.

[2] Russo F. \& Chilà G., Safety of users in road evacuation: demand models. Proc. of Urban Transport XIII, Urban Transport and the Environment in the 21 st century, Brebbia C.A. (ed.), WIT Press, Southampton, pp. 773-782, 2007.

[3] Russo F. \& Chilà G., Safety of users in road evacuation: RP vs. SP surveys in demand analysis. Proc. of Urban Transport XIV, Urban Transport and the Environment in the 21st century, Brebbia C.A. (ed.), WIT Press, Southampton, pp. 703-713, 2008.

[4] Russo F. \& Chilà G., Safety of users in road evacuation: Modelling and DSS for demand. Proc. of Sustainable Development and Planning IV, vol.1, Brebbia C.A. (ed.), WIT Press, Southampton, pp. 465-474, 2009.

[5] Russo F. \& Chilà G., Dynamic approaches to demand model in evacuation conditions. Proc. of Urban Transport XVI, Urban Transport and the Environment in the 21st century, Brebbia C.A. (ed.), WIT Press, Southampton, pp. 303-312, 2010.

[6] Russo F. \& Chilà G., A sequential dynamic choice model to simulate demand in evacuation conditions. Proc. of Risk analysis VII \& Brownfields $V$, Brebbia C.A. (ed.), WIT Press, Southampton, pp. 431-442, 2010.

[7] Vitetta A., Musolino G. \& Marcianò F.A., Safety of users in road evacuation: Supply and demand-supply interaction models for users. Proc. of Urban Transport XIII, Urban Transport and the Environment in the 21st century, Brebbia C.A. (ed.), WIT Press, Southampton, pp. 783-792, 2007.

[8] Vitetta A., Musolino G. \& Marcianò F.A., Safety of users in road evacuation: calibration of cost functions and simulation. Proc. of Urban 
Transport XIV, Urban Transport and the Environment in the 21st century, Brebbia C.A. (ed.), WIT Press, Southampton, pp. 715-725, 2008.

[9] Vitetta A., Quattrone A. \& Polimeni A., Safety of users in road evacuation: design of path choice models for emergency vehicles. Proc. of Urban Transport XIII, Urban Transport and the Environment in the 21st century, Brebbia C.A. (ed.), WIT Press, Southampton, pp. 803-812, 2007.

[10] Vitetta A., Quattrone A. \& Polimeni A., Safety of users in road evacuation: algorithms for path design of emergency vehicles, Proc. of Urban Transport XIV, Urban Transport and the Environment in the 21st century, Brebbia C.A. (ed.), WIT Press, Southampton, pp. 727-737, 2008.

[11] Russo F. \& Rindone C., Safety of users in road evacuation: planning internal processes and guidelines. Proc. of Urban Transport XIII, Urban Transport and the Environment in the 21st century, Brebbia C.A. (ed.), WIT Press, Southampton, pp. 825-834, 2007.

[12] Russo F. \& Rindone C., Safety of users in road evacuation: the logical framework approach in evacuation planning. Proc. of Urban Transport $X I V$, Urban Transport and the Environment in the 21st century, Brebbia C. A. (ed.), WIT Press, Southampton, pp. 751-760, 2008.

[13] Russo F. \& Rindone C., Safety of users in road evacuation: Modelling and DSS for LFA in the planning process. Proc. of Sustainable Development and Planning IV, vol.1, Brebbia C.A. (ed.), WIT Press, Southampton, pp. 453-464, 2009.

[14] Russo F. \& Rindone C., Evaluation methods for evacuation planning. Proc. of Urban Transport XVI, Urban Transport and the Environment in the 21 st century, Brebbia C.A. (ed.), WIT Press, Southampton, pp. 335-343, 2010.

[15] Russo, F. \& Rindone C., Data Envelopment Analysis (DEA) for evacuation planning. Proc. of Risk analysis VII \& Brownfields V, Brebbia C.A. (ed.), WIT Press, Southampton, pp.455-467, 2010.

[16] Bellman, RE. Dynamic Programming. Princeton University Press; reprinted 2010.

[17] Lawler EL., Combinatorial optimization: networks and matroids. Holt, Rinehart \& Wilson: New York; 1976.

[18] Russo F, Vitetta A., An assignment model with modified Logit, which obviates enumeration and overlapping problems. Transportation, 30 (2), pp. 177-201, 2003.

[19] Cooke K.L. \& Halsey E., The shortest route through a network with timedependent internodal transit times. Journal of Mathematical Analysis and Applications, 14(3), 493-498, 1966.

[20] Dreyfus S.E., An Appraisal of Some Shortest-Path Algorithms. Operations Research, 17(3), 395-412, 1969.

[21] Daganzo C.F., Reversibility of the time-dependent shortest path problem. Transportation Research Part B 2002; 36; 665-668.

[22] Dean B.C., Continuous-time shortest path algorithm. Massachusetts Institute of Technology, MSc thesis, 1999. 
[23] Dehne F., Omran M.T. \& Sack JR., Shortest Paths in Time-Dependent FIFO Networks. Algorithmica 2010; Online First ${ }^{\mathrm{TM}}, 28$ October 2010.

[24] Chabini I., Discrete dynamic shortest path problems in transportation applications: complexity and algorithms with optimal run time. Transportation Research Record: Journal of Transportation Research Board 1645, 170-175, 1998.

[25] Hall R.W., The fastest path through a network with random time-dependent travel times. Transportation Science, 20 (3), 182-188, 1986.

[26] Miller-Hooks E.D. \& Mahmassani H.S., Path comparisons for a priori and time adaptive decisions in stochastic, time-varying networks. Computers Operations Research, 146, 67-82, 2003.

[27] Pattanamekar P., Park D., Rilett L.R., Lee J. \& Lee C., Dynamic and stochastic shortest path in transportation networks with two components of travel time uncertainty. Transportation Research Part C, 11, 331-354,2003

[28] Ahuja R.K., Orlin J.B., Pallottino S. \& Scutellà M.G., Dynamic shortest paths minimizing travel times and costs. Networks, 4; 197-205, 2003.

[29] Bérubé J.F., Potvin J.Y. \& Vaucher J. Time-dependent shortest paths through a fixed sequence of nodes: application to a travel planning problem. Computers \& Operations Research, 33, 1838-1856, 2006.

[30] Orda A. \& Rom R., Shortest-path and minimum-delay algorithms in networks with time-dependent edge-length. Journal of the ACM 1990; 37; 607-625.

[31] Dell'Amico M., Iori M. \& Pretolani D., Shortest paths in piecewise continuous time-dependent networks. Operations Research Letters, 36, 688691, 2008.

[32] Russo F., Vitetta A. \& Polimeni A., From single path to vehicle routing problem: the retailer delivery approach. Procedia Social and Behavioral Sciences volume 2(3), pp. 6378-6386, 2010.

[33] Song R. HE, S. \& Zhang L., Optimum transit operations during the emergency evacuations. Journal of transportation systems engineering and information technology, 9(6), pp.154-160, 2009.

[34] Haghani A. \& Jung S., A dynamic vehicle routing problem with timedependent travel times. Computers \& Operations Research, 32, pp. 29592986, 2005.

[35] Chen H.K., Hsueh C.F. \& Chang M.S., The real-time time-dependent vehicle routing problem. Transportation Research Part E: Logistics and Transportation Review, 42(5), pp. 383 - 408, 2006.

[36] Musolino G. \& Vitetta A., Short-term forecasting in road evacuation: calibration of a travel time function. Proc. of Urban Transport XVII, Urban Transport and the Environment in the 21st century, Brebbia C. A. (ed.), WIT Press, Southampton, 2011.

[37] Russo F. \& Vitetta A., Reverse assignment: calibrating link cost functions and updating demand from traffic counts and time measurements. Inverse Problems in Science \& Engineering, ISSN 1741-5977 print/ISSN 17415985 Taylor \& Francis DOI: 10.1080/17415977.2011.565339, 2011. 